\title{
Bilateral Total Knee Arthroplasty Guidelines: Are We There Yet?
}

\author{
Ettore Vulcano, MD ${ }^{1}$ Stavros Memtsoudis, MD, $\mathrm{PhD}^{2} \quad$ Alejandro Gonzalez Della Valle, $\mathrm{MD}^{3}$
}

${ }^{1}$ Department of Orthopaedic Surgery, Universita' dell'Insubria,

Address for correspondence Ettore Vulcano, MD, Department of Varese, VA, Italy

2 Department of Anesthesiology, Hospital for Special Surgery, New York, New York Orthopaedic Surgery, Universita' dell'Insubria, Viale Borri 57 Varese,

3 Department of Orthopaedics, Hospital for Special Surgery, New York, New York

J Knee Surg 2013;26:273-280.

\begin{abstract}
Keywords

- bilateral knee replacement

- bilateral TKA

- bilateral TKA guidelines

- single-stage bilateral TKA

The proportion of bilateral total knee replacements (BTKR) to unilateral total knee replacement (UTKR) in the United States is increasing. From 1990 to 2004, the use of BTKRs more than doubled for the entire civilian population and almost tripled among the female population. BTKRs can be performed in a single-stage or a staged procedure. Supporters of single-stage BTKR point out its low complication rates, high patient satisfaction, and cost-effectiveness. Others strongly believe that BTKR performed during the same anesthetic session is associated with increased morbidity and mortality. Single-stage BTKR surgery aims at reducing the exposure to repeated anesthesia, total hospitalization and recovery time, and cost, while maintaining patient safety and reducing the negative clinical and functional outcomes observed in patients undergoing UTKR or staged BTKR. This article presents the current concepts and controversies around BTKR surgery based on the authors' body of research and a review of the literature. We also present our institutional guidelines for candidates for singlestage BTKR.
\end{abstract}

Approximately $20 \%$ of patients undergoing primary unilateral total knee replacements (UTKR) complain of severe pain in the contralateral knee, ${ }^{1}$ and $10 \%$ of patients who have had a primary total knee replacements (TKR) would undergo contralateral TKR surgery within 1 year. $^{2}$

The proportion of bilateral total knee replacements (BTKR) to UTKR in the United States is increasing. We estimated the rate of BTKR / UTKR + BTKR to be 4\% between 1990 and 1994 and $6.5 \%$ in the period between 1998 and $2006 .{ }^{3}$ From 1990 to 2004, 20.2\% of BTKRs were performed between 1990 and 1994, 28.7\% between 1995 and 1999, and 51.1\% between 2000 and 2004. From 1990 to 2004, the use of BTKRs more than doubled for the entire civilian population and almost tripled among the female population. ${ }^{4}$
These trends may be driven by the expansion of indications for TKR to younger, healthier, more active patients and the epidemic of obesity and its consequences in the progression of osteoarthritis, ${ }^{3,5-8}$ all these factors resulting in a higher demand for the procedure. Advances in anesthesia, surgery, and perioperative care may further contribute to the increase in the use of BTKR. ${ }^{4}$

The supporters of single-stage BTKR point out its low complication rates, high patient satisfaction, and cost-effectiveness. $^{8-15}$ Others strongly believe that BTKR performed during the same anesthetic session is associated with increased morbidity and mortality. ${ }^{14-21}$

The objective of single-stage BTKR surgery is to reduce the exposure to repeated anesthesia, total hospitalization and received

May 21, 2012

accepted after revision

September 12, 2012

published online

January 2, 2013
Copyright $\odot 2013$ by Thieme Medical Publishers, Inc., 333 Seventh Avenue, New York, NY 10001, USA. Tel: +1(212) 584-4662.
DOI http://dx.doi.org/ 10.1055/s-0032-1329721. ISSN 1538-8506. 
recovery time, and cost, while maintaining patient safety, and to reduce the negative clinical and functional outcomes observed in patients undergoing UTKR or staged BTKR. ${ }^{10,11,22-36}$ However, in light of the divided opinions on the use of single-stage BTKR surgery, thorough patient selection seems to be the safest clinical approach. $8,16,37-39$

The aim of this article is to present the current concepts and controversies around BTKR surgery based on the authors' body of research and a review of the literature.

\section{Advantages of Single-Stage Bilateral Total Knee Replacement The Use of One Anesthetic Session}

Despite the low rate of major complications associated with anesthesia, the risks of potential procedures (i.e., endotracheal intubation in the case of general anesthetic, neuraxial complications with a regional technique), and those associated with the administration of drugs and insertions of invasive lines cannot be discounted completely. Hence, from an anesthetic procedural aspect, the avoidance of a second exposure is beneficial.

\section{Shorter Surgical Time}

Surgical time varies with the type of BTKR performed. Liu et $\mathrm{al}^{40}$ reported that the mean operative and tourniquet time for patients undergoing sequential procedures was 19 minutes and 26 minutes shorter than for those undergoing staged BTKR, respectively. This reflects in lower operating room costs and in the reduction of potential risks associated with tourniquet application, such as nerve palsy, vascular injury, muscle damage, and postoperative swelling and stiffness. ${ }^{41-47}$ Less frequent complications have also been observed with tourniquet use, such as, intraoperative cardiac arrest at the time of deflation, reactive hyperemia, early infection and wound healing disorders due to perioperative hypoxia, and reduced postoperative tissue perfusion. ${ }^{48-53}$

\section{Diminished Use of Pain Medication}

Some authors have challenged the belief that patients undergoing single-stage BTKR experience worse pain and have a higher requirement for narcotics than those undergoing UTKR. ${ }^{17,54,55}$ Powell et al observed that narcotic requirements were not significantly different for the simultaneous BTKR group compared with a UTKR group during the first 72 hours after surgery. ${ }^{54}$ Shetty et al prospectively studied 50 patients undergoing sequential BTKR and 50 patients undergoing UTKR. ${ }^{55}$ The mean difference in postoperative VAS scores was significant only on the first postoperative day.

\section{Lower Cost}

Several authors ${ }^{9,23,26,30}$ showed that single-stage BTKR results in overall savings in the range of 18 to $58 \%$ compared with the cost of staged procedures. The economic benefit of single-stage BTKR surgery arises from shorter hospital stay, ${ }^{25,56}$ lower charges for laboratory tests, medical consultations, operating room costs, anesthesia and surgical fees, recovery room time, antibiotics, and physical therapy. ${ }^{14}$ One study $^{56}$ reported that the proportion of patients being discharged to a rehabilitation center was higher in the simultaneous BTKR group (55\%) than in the UTKR group (33\%). Nonetheless, the proportion of patients readmitted within 12 months of surgery for condition related to the knee surgery was higher in the UTKR group (12\%) than in the BTKR group (5\%).

\section{Excellent Clinical Results and Patient Satisfaction}

Five studies ${ }^{12,14,17,56,57}$ reporting on the clinical results of BTKR patients argue that single-stage BTKR is very successful. BTKR patients demonstrated similar or better results in terms of range of motion, ${ }^{17}$ Oxford Knee Score, ${ }^{17}$ Knee Society Score $(\mathrm{KSS}),{ }^{57}$ survivorship at 7 years ${ }^{14}$ and 10 years, ${ }^{12}$ and patientdriven outcome tools like the Western Ontario and McMaster Universities Arthritis Index, ${ }^{56}$ and the 36- and 12-Item Short Form Health Survey (SF-36 $6^{56}$ and SF-12 ${ }^{57}$ ). Patient satisfaction and health perception are clear advantages of singlestage BTKR, with $95 \%$ of patients who would opt for the same procedure again. ${ }^{14}$ Other authors observed that patients undergoing simultaneous BTKR have improved physical and social function, less pain, and better general and mental health than patients undergoing UTKR. ${ }^{56}$

A large survival analysis ${ }^{10}$ on 2,050 simultaneous BTKR patients, 152 staged BTKR patients (performed within 1 year), and 1,796 UTKR patients at 5,10 , and 15 years postoperatively concluded that patients who had undergone UTKR had significantly lower KSS compared with patients with simultaneous BTKR.

\section{Concerns with Single-Stage Bilateral Total Knee Replacement}

We reviewed a total of 33 comparative studies on BTKR surgery. ${ }^{58}$ Seven studies reported significant differences in local complication rates: Three studies observed higher complication rates in the UTKR group with respect to either single-stage or staged BTKR groups ${ }^{10,25,59}$; four studies observed higher local complication rates in the single-stage BTKR groups than in the UTKR group $3,10,60,61$; and two studies reported higher local complication rates in the staged BTKR group versus the UTKR group. ${ }^{3,60}$ Finally, one study observed higher local complication rates in the staged BTKR group compared with the single-stage BTKR group. ${ }^{62}$

In terms of systemic complications, 17 studies observed significant differences between the study groups. Twelve studies observed higher systemic complication rates in the single-stage BTKR group compared with the UTKR group $^{3,10,15,16,18,25,56,60,61,63-65}$; one study reported higher systemic complication rates in the UTKR patients than in the staged BTKR patients ${ }^{59}$; and three studies reported higher systemic complication rates in the staged BTKR group versus the single-stage group. ${ }^{3,34,62}$ Furthermore, one study observed that nosocomial infections were significantly lower in the 3-month staged BTKR group with respect to singlestage BTKR and 6-week/6-month/12-month staged BTKR groups. ${ }^{62}$ Finally, one study reported higher systemic complication rates in the single-stage BTKR group than in staged 
BTKR patients, ${ }^{66}$ and one study observed increased systemic complication rates in BTKR patients (all groups) with respect to UTKR patients. ${ }^{67}$

Regarding mortality rate, four studies recorded significant differences among groups. Specifically, one study observed increased mortality rates in the single-stage BTKR groups versus both UTKR and staged BTKR recipients only if older than 75 years of age ${ }^{68}$; one study reported higher mortality rates in the single-stage group compared with the staged procedures groups ${ }^{60}$; and two studies observed increased mortality rates in either single-stage or staged BTKR groups compared with UTKR group. ${ }^{3,19}$

\section{Increased Risk of Cardiac Complications}

Several authors have reported an increased risk of cardiac complications in patients undergoing single-stage BTKR. ${ }^{10,11,33,63,64}$ Indeed, myocardial ischemia was found to be 4 to 6 times more frequent in single-stage BTKR patients than in UTKR patients. ${ }^{16,63,64}$ Our institutional experience $^{37,65}$ showed that single-stage BTKR is associated with a significantly higher risk of cardiovascular complications especially in patients with medical comorbidities such as pulmonary hypertension, congestive heart failure, chronic pulmonary disease, and renal disease. Patients with reduced end-organ reserve, and thus decreased ability to compensate for these insults, may be at high risk. ${ }^{3}$

\section{Increased Risk of Pulmonary Complications including Thromboembolism}

Fat and pulmonary emboli are more frequent in patients undergoing single-stage BTKR than in those undergoing UTKR. Some authors suggested using a fluted intramedullary rod, slow rod insertion technique, and overdrilling the entry point for the guide $\operatorname{rod}^{28,69,70}$ to reduce such risk. However, others have discredited this theory. ${ }^{18}$

The increased risk of thromboembolism seems to be related with the prolonged operating time of single-stage BTKR, the cementing of the components, the surgical intervention at both lower extremities, and a prolonged duration of relative immobility, ${ }^{71}$ all of which contribute to trigger the Virchow triad. ${ }^{72}$ Our study of inhospital complications of TKR surgery ${ }^{5}$ demonstrated a $50 \%$ increased risk of pulmonary embolism (PE) in patients undergoing BTKR as opposed to UTKR. Similarly, other authors reported an $80 \%$ higher adjusted risk of PE in the BTKR group ${ }^{73}$ and an increased risk of PE in single-stage BTKR patients. ${ }^{74}$ Although most studies warn of a higher risk of $P E$ in patients undergoing single-stage BTKR, one investigation reported a similar rate of asymptomatic deep venous thrombosis (41\%) in single-stage BTKR and UTKR patients not receiving thromboprophylaxis. ${ }^{75}$

Given the fact that most studies have observed a higher risk of pulmonary complications including thromboembolism, it seems prudent to screen patients who are suspected of having increased pulmonary pressure or right heart dysfunction, including patients with sleep apnea and those with a history of PE, and to consider them at a high risk. These conditions may be associated with higher impedance to venous return due to increases in right heart pressures, especially after additional increases in pulmonary vascular resistance brought on by embolizing debris after bilateral procedures. ${ }^{76-79}$

\section{Increased Perioperative Mortality}

One study ${ }^{62}$ reviewing 62,730 BTKRs reported a 30-day mortality rate of $0.33 \%$ for staged BTKR as opposed to $0.99 \%$ for simultaneous BTKR $(p<0.05)$. Parvizi et al ${ }^{19}$ reviewed 19,861 UTKRs and 2,679 single-stage BTKRs performed at their institution, reporting a 30 -day mortality rate of $0.17 \%$ and $0.49 \%$, respectively $(p<0.05)$. However, other authors ${ }^{12}$ reported that the 90-day mortality rate of 2,385 sequential BTKR patients $(0.3 \%)$ and 719 UTKR patients $(0.7 \%)$ was comparable.

In our analysis of the National Hospital Discharge Survey, ${ }^{5}$ we found that the inhospital mortality rate of BTKR patients $(0.5 \%)$ was higher than that of patients undergoing UTKR (0.3\%). The discrepancy in mortality between BTKR and UTKR was confirmed in our most recent analysis of the Nationwide Inpatient Sample. ${ }^{3}$

\section{Increased Risk of Postoperative Confusion}

Postoperative confusion rate after single-stage BTKR, compared with UTKR, is higher. ${ }^{5,18,80,81}$ The cause for this complication seems to be strongly related to the higher degree of systemic inflammation and higher rates of fat/debris embolization. ${ }^{18,82}$ Some researchers have conducted intraoperative hemodynamic monitoring, electroencephalography, and direct ultrasound imaging of the carotid artery in patients undergoing bilateral lower limb replacements, observing debris embolization into the arterial circulation especially on tourniquet deflation immediately after the second of two sequential arthroplasty procedures. ${ }^{82,83}$

\section{Potential Increase in Wound Infection Rate}

The literature is divided with respect to wound infection rates following single-stage BTKR and UTKR. ${ }^{25,61,66}$ Authors who have observed a higher infection rate in single-stage BTKR surgery ${ }^{25,61}$ blame the longer operating times, increased number of medical personnel in the operating room, and no rescrubbing, no redraping, and no instrument change for the second knee arthroplasty.

We studied deep and superficial wound infection rates 1 year after single-stage bilateral total hip arthroplasties performed with one or two sets of sterile instruments. ${ }^{84}$ The rate of infection was similar.

Some authors suggested that BTKR surgery has a lower risk of perioperative infection compared with UTKR. A large retrospective cohort study observed a significantly lower rate of superficial infection risk for BTKR (0.3\%) compared with UTKRs $(0.8 \%){ }^{10}$ Likewise, our study on inhospital complications ${ }^{5}$ showed that despite the higher rate of obesity in patients undergoing BTKR (8.3\% vs. $6.3 \%$ in UTKR patients), those undergoing UTKR had higher rates of procedure-related inhospital infection ( $0.1 \%$ vs. $0.2 \%$ in the UTKR group). The cause may lie in the fact that the UTKR group had an increased prevalence of other comorbidities, some of which responsible for increased risk of infection, that is, diabetes. ${ }^{85}$ 


\section{Increased Use of Allogenic Blood Transfusions}

Utilizing nationally representative data, we found the incidence of postoperative anemia to be around $28.6 \%$ in BTKR and $15.3 \%$ in UTKR patients. ${ }^{3}$ The increased risk of allogenic blood transfusions after single-stage BTKR has been reported to be as high as 17 -fold. $5,15,18,37,86$ To limit the need for allogenic blood transfusion, some authors recommended the use of a cell saver. ${ }^{87}$

\section{Increased Discharges to Rehabilitation Centers}

With respect to UTKR surgery, an increased proportion of patients undergoing single-stage BTKR surgery are discharged to a rehabilitation facility. ${ }^{5,9,17,18,54,63}$ In our previously mentioned study, ${ }^{5}$ we observed that $37.2 \%$ of BTKR patients in comparison to $19.6 \%$ of UTKR patients was discharged to short- or long-term facilities. The reason for this seems to lie not solely in the slower postoperative mobilization of patients undergoing BTKR, but also in surgeon, physical therapist, and social worker expectation that dedicated rehabilitation after the hospital stay would be more frequently necessary in BTKR compared with UTKR patients.

\section{Optimum Time between Surgeries}

The literature provides evidence in support of BTKR surgery performed under a single anesthetic providing that certain patient selection and safety measures are met. We observed that among patients undergoing BTKR during the same hospitalization, $74.8 \%$ were performed under the same anesthetic, whereas the remainder was performed on separate days of the hospital admission. ${ }^{3}$ Procedure-related complications were significantly less frequent in single-stage BTKR patients. However, venous thrombosis and PE occurred significantly more frequently among single-stage procedure recipients ( $1.48 \%$ vs. $1.22 \%$ and $0.89 \%$ vs. $0.77 \%$, respectively). No statistical difference in the rates of inhospital mortality was seen between groups.

Ritter et al investigated on the ideal timing between surgeries for BTKR candidates. ${ }^{62}$ Their data on over 63,000 BTKRs performed at different times apart suggested that none of the bilateral groups performed categorically better than the others, although 3-month staged BTKR was associated with the most favorable profile. This data are especially important in light of findings by other authors, reporting that patients with equally severe bilateral knee osteoarthritis have a $75 \%$ probability of having both knees replaced within 1 year of each other. ${ }^{88}$

\section{Hospital for Special Surgery Guidelines}

In light of the presented facts, thorough patient selection for BTKR surgery is crucial. In one study to identify risk factors for morbidity and mortality following BTKR surgery, ${ }^{77}$ we observed that $9.5 \%$ of patients developed major complications or mortality during their hospitalization. In accordance with other authors, ${ }^{19,67}$ increasing age was found to be an independent risk factor for major morbidity and mortality. Male gender was associated with increased risk of adverse outcome.
Our institutional experience and critical review of the literature has led to the creation of guidelines for the selection of appropriate candidates for single-stage BTKR, in a desire to reconcile benefits and concerns for safety. Although conclusive evidence is unavailable, the following points should be considered when contemplating single-stage BTKR:

1. The age of the patient. Several studies ${ }^{10,19,63-65,67,89-92}$ support that single-stage BTKR surgery in patients of extreme age should be avoided.

2. The patient's American Society of Anesthesiologists (ASA) classification. The findings of several authors $^{37,65,66,77,89,93}$ support the exclusion of patients with significant end organ dysfunction (i.e., ASA $\geq 3$ ).

3. Patients' comorbidities. Patients at risk for occult derangements of pulmonary hemodynamics and right heart dysfunction (i.e., morbidly obese, sleep apnea, chronic obstructive pulmonary disease, previous PE) should undergo cardiopulmonary evaluation with echocardiography to rule out significant preexisting increases in pulmonary artery pressures. Besides pulmonary hypertension, congestive heart failure, and chronic lung disease, other comorbidities should be used as exclusion criteria, including coronary artery disease, renal failure, neurological disease, hepatic dysfunction, and coagulopathies.

\section{Conclusions}

Single-stage BTKR is a valuable option for the treatment of debilitating bilateral knee osteoarthritis in the carefully selected patient. Benefits of this procedure include excellent clinical results, the use of a single anesthetic, a shorter overall surgical time, similar or less pain with respect to UTKR, and lower overall use of narcotics. Also, shorter overall recovery time accelerates return to everyday life and work. Patient satisfaction is qualitatively and quantitatively at least equivalent to that of UTKR, with the overwhelming majority of patients who have experienced single-stage BTKR declaring they would opt for the same procedure again. Finally, costeffectiveness of single-stage BTKR represents a major advantage of the procedure, with overall savings reaching up to 58\% compared with the cost of staged procedures.

However, the disadvantages of single-stage BTKR should not be disregarded when evaluating a potential candidate. The higher mortality and life-threatening cardiopulmonary complication rates in single-stage BTKR compared with UTKR patients must be weighed against the previously mentioned advantages when recommending this surgical approach.

\section{References}

1 Mont MA, Mitzner DL, Jones LC, Hungerford DS. History of the contralateral knee after primary knee arthroplasty for osteoarthritis. Clin Orthop Relat Res 1995;321(321):145-150

2 Walmsley P, Murray A, Brenkel IJ. The practice of bilateral, simultaneous total knee replacement in Scotland over the last decade. Data from the Scottish Arthroplasty Project. Knee 2006;13 (2):102-105 
3 Memtsoudis SG, Ma Y, González Della Valle A, et al. Perioperative outcomes after unilateral and bilateral total knee arthroplasty. Anesthesiology 2009;111(6):1206-1216

4 Memtsoudis SG, Besculides MC, Reid S, Gaber-Baylis LK, González Della Valle A. Trends in bilateral total knee arthroplasties: 153,259 discharges between 1990 and 2004. Clin Orthop Relat Res 2009;467(6):1568-1576

5 Memtsoudis SG, González Della Valle A, Besculides MC, Gaber L, Sculco TP. In-hospital complications and mortality of unilateral, bilateral, and revision TKA: based on an estimate of 4,159,661 discharges. Clin Orthop Relat Res 2008;466(11):2617-2627

6 Memtsoudis SG, Starcher B, González Della Valle A, Ma Y, JulesElysee K, Sculco TP. Urine desmosine as a marker of lung injury following total knee arthroplasty. A pilot study. HSS J 2009;5 (2):154-158

7 Hunter DJ, March L, Sambrook PN. Knee osteoarthritis: the influence of environmental factors. Clin Exp Rheumatol 2002;20 (1):93-100

8 Alemparte J, Johnson GV, Worland RL, Jessup DE, Keenan J. Results of simultaneous bilateral total knee replacement: a study of 1208 knees in 604 patients. J South Orthop Assoc 2002;11(3):153-156

9 Reuben JD, Meyers SJ, Cox DD, Elliott M, Watson M, Shim SD. Cost comparison between bilateral simultaneous, staged, and unilateral total joint arthroplasty. J Arthroplasty 1998;13(2):172-179

10 Ritter MA, Harty LD, Davis KE, Meding JB, Berend M. Simultaneous bilateral, staged bilateral, and unilateral total knee arthroplasty. A survival analysis. J Bone Joint Surg Am 2003;85-A(8):1532-1537

11 Morrey BF, Adams RA, Ilstrup DM, Bryan RS. Complications and mortality associated with bilateral or unilateral total knee arthroplasty. J Bone Joint Surg Am 1987;69(4):484-488

$12 \mathrm{Kim}$ YH, Choi YW, Kim JS. Simultaneous bilateral sequential total knee replacement is as safe as unilateral total knee replacement. J Bone Joint Surg Br 2009;91(1):64-68

13 Husted H, Troelsen A, Otte KS, Kristensen BB, Holm G, Kehlet H. Fast-track surgery for bilateral total knee replacement. J Bone Joint Surg Br 2011;93(3):351-356

14 Leonard L, Williamson DM, Ivory JP, Jennison C. An evaluation of the safety and efficacy of simultaneous bilateral total knee arthroplasty. J Arthroplasty 2003;18(8):972-978

15 Lombardi AV, Mallory TH, Fada RA, et al. Simultaneous bilateral total knee arthroplasties: who decides? Clin Orthop Relat Res 2001;(392):319-329

16 Bullock DP, Sporer SM, Shirreffs TG Jr. Comparison of simultaneous bilateral with unilateral total knee arthroplasty in terms of perioperative complications. J Bone Joint Surg Am 2003;85-A (10):1981-1986

17 Fick D, Crane T, Shakespeare D. A comparison of bilateral vs. unilateral total knee arthroplasty mobilised using a flexion regime. Knee 2002;9(4):285-289

18 Lane GJ, Hozack WJ, Shah S, et al. Simultaneous bilateral versus unilateral total knee arthroplasty. Outcomes analysis. Clin Orthop Relat Res 1997;345(345):106-112

19 Parvizi J, Sullivan TA, Trousdale RT, Lewallen DG. Thirty-day mortality after total knee arthroplasty. J Bone Joint Surg Am 2001;83-A(8):1157-1161

$20 \mathrm{Kim}$ YH. Incidence of fat embolism syndrome after cemented or cementless bilateral simultaneous and unilateral total knee arthroplasty. J Arthroplasty 2001;16(6):730-739

21 Sulek CA, Davies LK, Enneking FK, Gearen PA, Lobato EB. Cerebral microembolism diagnosed by transcranial Doppler during total knee arthroplasty: correlation with transesophageal echocardiography. Anesthesiology 1999;91(3):672-676

22 Benjamin J, Tucker T, Ballesteros P. Is obesity a contraindication to bilateral total knee arthroplasties under one anesthetic? Clin Orthop Relat Res 2001;392(392):190-195

23 Brotherton SL, Roberson JR, de Andrade JR, Fleming LL. Staged versus simultaneous bilateral total knee replacement. J Arthroplasty $1986 ; 1(4): 221-228$
24 Cohen RG, Forrest CJ, Benjamin JB. Safety and efficacy of bilateral total knee arthroplasty. J Arthroplasty 1997;12(5):497-502

25 Gradillas EL, Volz RG. Bilateral total knee replacement under one anesthetic. Clin Orthop Relat Res 1979;140(140):153-158

26 Hardaker WT Jr, Ogden WS, Musgrave RE, Goldner JL. Simultaneous and staged bilateral total knee arthroplasty. J Bone Joint Surg Am 1978;60(2):247-250

27 Jankiewicz JJ, Sculco TP, Ranawat CS, Behr C, Tarrentino S. Onestage versus 2-stage bilateral total knee arthroplasty. Clin Orthop Relat Res 1994;309(309):94-101

28 Kolettis GT, Wixson RL, Peruzzi WT, Blake MJ, Wardell S, Stulberg SD. Safety of 1-stage bilateral total knee arthroplasty. Clin Orthop Relat Res 1994;309(309):102-109

29 McLaughlin TP, Fisher RL. Bilateral total knee arthroplasties. Comparison of simultaneous (two-team), sequential, and staged knee replacements. Clin Orthop Relat Res 1985;199(199):220-225

30 Ritter MA, Meding JB. Bilateral simultaneous total knee arthroplasty. J Arthroplasty 1987;2(3):185-189

31 Ritter MA. Simultaneous knee replacement is better for the patient. Orthopedics 1998;21(4):415, 418

32 Ritter MA. Bilateral simultaneous TKR: doing what's best for the patient. Orthopedics 2000;23(6):538

33 Ritter MA, Harty LD. Debate: simultaneous bilateral knee replacements: the outcomes justify its use. Clin Orthop Relat Res 2004;428(428):84-86

34 Soudry M, Binazzi R, Insall JN, Nordstrom TJ, Pellicci PM, Goulet JA. Successive bilateral total knee replacement. J Bone Joint Surg Am 1985;67(4):573-576

35 Stanley D, Stockley I, Getty CJ. Simultaneous or staged bilateral total knee replacements in rheumatoid arthritis. A prospective study. J Bone Joint Surg Br 1990;72(5):772-774

36 Vince KG. Bilateral total knee arthroplasty under one anesthesia: a safe protocol. Mayo Clin Proc 1997;72(9):883-885

37 Pavone V, Johnson T, Saulog PS, Sculco TP, Bottner F. Perioperative morbidity in bilateral one-stage total knee replacements. Clin Orthop Relat Res 2004;(421):155-161

38 Forster MC, Bauze AJ, Bailie AG, Falworth MS, Oakeshott RD. A retrospective comparative study of bilateral total knee replacement staged at a one-week interval. J Bone Joint Surg Br 2006;88 (8):1006-1010

39 Taylor BC, Dimitris C, Mowbray JG, Gaines ST, Steensen RN. Perioperative safety of two-team simultaneous bilateral total knee arthroplasty in the obese patient. J Orthop Surg 2010;5:38

40 Liu TK, Chen SH. Simultaneous bilateral total knee arthroplasty in a single procedure. Int Orthop 1998;22(6):390-393

41 Abdel-Salam A, Eyres KS. Effects of tourniquet during total knee arthroplasty. A prospective randomised study. J Bone Joint Surg Br 1995;77(2):250-253

42 Klenerman L. Is a tourniquet really necessary for total knee replacement. J Bone Joint Surg Br 1995;77-B:174-175

43 Pedowitz RA. Tourniquet-induced neuromuscular injury. A recent review of rabbit and clinical experiments. Acta Orthop Scand Suppl 1991;245:1-33

44 Shaw JA, Murray DG. The relationship between tourniquet pressure and underlying soft-tissue pressure in the thigh. J Bone Joint Surg Am 1982;64(8):1148-1152

45 Sapega AA, Heppenstall RB, Chance B, Park YS, Sokolow D. Optimizing tourniquet application and release times in extremity surgery. A biochemical and ultrastructural study. J Bone Joint Surg Am 1985;67(2):303-314

46 Saunders KC, Louis DL, Weingarden SI, Waylonis GW. Effect of tourniquet time on postoperative quadriceps function. Clin Orthop Relat Res 1979;143(143):194-199

47 Patterson S, Klenerman L. The effect of pneumatic tourniquets on the ultrastructure of skeletal muscle. J Bone Joint Surg Br 1979;61$\mathrm{B}(2): 178-183$

48 Klenerman L. The tourniquet in surgery. J Bone Joint Surg $\mathrm{Br}$ 1962;44-B:937-943 
49 Klenerman L. The tourniquet in operations on the knee: a review. J R Soc Med 1982;75(1):31-32

50 Padala PR, Rouholamin E, Mehta RL. The role of drains and tourniquets in primary total knee replacement: a comparative study of TKR performed with drains and tourniquet versus no drains and adrenaline and saline infiltration. J Knee Surg 2004;17 (1):24-27

51 McGrath BJ, Hsia J, Epstein B. Massive pulmonary embolism following tourniquet deflation. Anesthesiology 1991;74(3):618620

52 Lundgren CE, Zederfeldt BH. Influence of low oxygen pressure on wound healing. Acta Chir Scand 1969;135(7):555-558

53 Stephens FO, Hunt TK. Effect of changes in inspired oxygen and carbon dioxide tensions on wound tensile strength: an experimental study. Ann Surg 1971;173(4):515-519

54 Powell RS, Pulido P, Tuason MS, Colwell CW Jr, Ezzet KA. Bilateral vs unilateral total knee arthroplasty: a patient-based comparison of pain levels and recovery of ambulatory skills. J Arthroplasty 2006;21(5):642-649

55 Shetty GM, Mullaji A, Bhayde S, Chandra Vadapalli R, Desai D. Simultaneous bilateral versus unilateral computer-assisted total knee arthroplasty: a prospective comparison of early postoperative pain and functional recovery. Knee 2010;17(3):191-195

56 March LM, Cross M, Tribe KL, et al; Arthritis C.O.S.T. Study Project Group. Two knees or not two knees? Patient costs and outcomes following bilateral and unilateral total knee joint replacement surgery for OA. Osteoarthritis Cartilage 2004;12(5):400-408

57 Stubbs G, Pryke SE, Tewari S, et al. Safety and cost benefits of bilateral total knee replacement in an acute hospital. ANZ J Surg 2005;75(9):739-746

58 Vulcano E, Gonzalez Della Valle A, Memtsoudis S. Benefits and drawback of bilateral total knee replacement surgery. In: MacKenzie R, Cornell C, Memtsoudis S, eds. Perioperative Care of the Orthopedic Patient. New York: Springer; 2013

59 Sliva CD, Callaghan JJ, Goetz DD, Taylor SG. Staggered bilateral total knee arthroplasty performed four to seven days apart during a single hospitalization. J Bone Joint Surg Am 2005;87(3):508-513

60 Hutchinson JR, Parish EN, Cross MJ. A comparison of bilateral uncemented total knee arthroplasty: simultaneous or staged? J Bone Joint Surg Br 2006;88(1):40-43

61 Luscombe JC, Theivendran K, Abudu A, Carter SR. The relative safety of one-stage bilateral total knee arthroplasty. Int Orthop 2009;33(1):101-104

62 Ritter M, Mamlin LA, Melfi CA, Katz BP, Freund DA, Arthur DS. Outcome implications for the timing of bilateral total knee arthroplasties. Clin Orthop Relat Res 1997;(345):99-105

63 Adili A, Bhandari M, Petruccelli D, De Beer J. Sequential bilateral total knee arthroplasty under 1 anesthetic in patients $>$ or $=75$ years old: complications and functional outcomes. J Arthroplasty 2001;16(3):271-278

64 Lynch NM, Trousdale RT, Ilstrup DM. Complications after concomitant bilateral total knee arthroplasty in elderly patients. Mayo Clin Proc 1997;72(9):799-805

65 Urban MK, Chisholm M, Wukovits B. Are postoperative complications more common with single-stage bilateral (SBTKR) than with unilateral knee arthroplasty: guidelines for patients scheduled for SBTKR. HSS J 2006;2(1):78-82

66 Yoon HS, Han CD, Yang IH. Comparison of simultaneous bilateral and staged bilateral total knee arthroplasty in terms of perioperative complications. J Arthroplasty 2010;25(2):179-185

67 Mantilla CB, Horlocker TT, Schroeder DR, Berry DJ, Brown DL. Frequency of myocardial infarction, pulmonary embolism, deep venous thrombosis, and death following primary hip or knee arthroplasty. Anesthesiology 2002;96(5):1140-1146

68 Mangaleshkar SR, Prasad PS, Chugh S, Thomas AP. Staged bilateral total knee replacement-a safer approach in older patients. Knee 2001;8(3):207-211
69 Fahmy NR, Chandler HP, Danylchuk K, Matta EB, Sunder N, Siliski JM. Blood-gas and circulatory changes during total knee replacement. Role of the intramedullary alignment rod. J Bone Joint Surg Am 1990;72(1):19-26

70 Ries MD, Rauscher LA, Hoskins S, Lott D, Richman JA, Lynch F Jr. Intramedullary pressure and pulmonary function during total knee arthroplasty. Clin Orthop Relat Res 1998;(356): 154-160

71 Patil N, Wakankar H. Morbidity and mortality of simultaneous bilateral total knee arthroplasty. Orthopedics 2008;31(8):780789, quiz 790-791

72 Virchow RLK, ed. Thrombosis and Emboli (1846-1856). Matzdorff AC, Bell WR, trans. Canton: Science History Publications; 1998:511,110

73 Barrett J, Baron JA, Losina E, Wright J, Mahomed NN, Katz JN. Bilateral total knee replacement: staging and pulmonary embolism. J Bone Joint Surg Am 2006;88(10):2146-2151

74 Restrepo C, Parvizi J, Dietrich T, Einhorn TA. Safety of simultaneous bilateral total knee arthroplasty. A meta-analysis. J Bone Joint Surg Am 2007;89(6):1220-1226

$75 \mathrm{Kim}$ YH, Kim JS. Incidence and natural history of deep-vein thrombosis after total knee arthroplasty. A prospective, randomised study. J Bone Joint Surg Br 2002;84(4):566-570

76 Memtsoudis SG, Salvati EA, Go G, Ma Y, Sharrock NE. Perioperative pulmonary circulatory changes during bilateral total hip arthroplasty under regional anesthesia. Reg Anesth Pain Med 2010;35 (5):417-421

77 Memtsoudis SG, Ma Y, Chiu YL, Poultsides L, Gonzalez Della Valle A Mazumdar M. Bilateral total knee arthroplasty: risk factors for major morbidity and mortality. Anesth Analg 2011;113(4):784790

78 Bradley TD. Right and left ventricular functional impairment and sleep apnea. Clin Chest Med 1992;13(3):459-479

79 Kline JA, Steuerwald MT, Marchick MR, Hernandez-Nino J, Rose GA. Prospective evaluation of right ventricular function and functional status 6 months after acute submassive pulmonary embolism: frequency of persistent or subsequent elevation in estimated pulmonary artery pressure. Chest 2009;136(5):12021210

80 Worland RL, Jessup DE, Clelland C. Simultaneous bilateral total knee replacement versus unilateral replacement. Am J Orthop 1996;25(4):292-295

81 Oakes DA, Hanssen AD. Bilateral total knee replacement using the same anesthetic is not justified by assessment of the risks. Clin Orthop Relat Res 2004;(428):87-91

82 Weiss SJ, Cheung AT, Stecker MM, Garino JP, Hughes JE, Murphy FL. Fatal paradoxical cerebral embolization during bilateral knee arthroplasty. Anesthesiology 1996;84(3):721-723

83 Edmonds CR, Barbut D, Hager D, Sharrock NE. Intraoperative cerebral arterial embolization during total hip arthroplasty. Anesthesiology 2000;93(2):315-318

84 González Della Valle A, Walter WL, Peterson MG, Pellicci PM, Sculco TP, Salvati EA. Prevalence of infection in bilateral total hip arthroplasty: a comparison of single-stage 565 bilateral procedures performed with 1 or 2 sets of instruments. J Arthroplasty 2006;21(2):157-160

85 Meding JB, Reddleman K, Keating ME, et al. Total knee replacement in patients with diabetes mellitus. Clin Orthop Relat Res 2003; (416):208-216

86 Bottner F, Pavone V, Johnson T, Heitkemper S, Sculco TP. Blood management after bilateral total knee arthroplasty. Clin Orthop Relat Res 2003;(410):254-261

87 Breakwell LM, Getty CJ, Dobson P. The efficacy of autologous blood transfusion in bilateral total knee arthroplasty. Knee 2000;7 (3):145-147

88 Minter JE, Dorr LD. Indications for bilateral total knee replacement. Contemp Orthop 1995;31(2):108-111 
89 Memtsoudis SG, Besculides MC, Gaber L, Liu S, González Della Valle A. Risk factors for pulmonary embolism after hip and knee arthroplasty: a population-based study. Int Orthop 2009;33 (6):1739-1745

90 Laskin RS. Total knee replacement in patients older than 85 years. Clin Orthop Relat Res 1999;(367):43-49
91 Adam RF, Noble J. Primary total knee arthroplasty in the elderly. J Arthroplasty 1994;9(5):495-497

92 Hosick WB, Lotke PA, Baldwin A. Total knee arthroplasty in patients 80 years of age and older. Clin Orthop Relat Res 1994;299(299):77-80

93 Noble J, Goodall JR, Noble DJ. Simultaneous bilateral total knee replacement: a persistent controversy. Knee 2009;16(6):420-426 